have recently overcome this difficulty by using a light frame of very fine wire so as to divide the scalp into four areas-viz., the vertex, two lateral, and the occiput. The framework being adjusted the line of the wires is marked on the scalp with a skin pencil so that their position may be kept constant. It is then easy to surround each area to be exposed by sheets of lead foil folded round the wires. The frame is made simply of three pieces of wire, as in Fig. 1, and is fixed by tying with tapes at the nape and across the forehead, as in Fig. 2, thus dividing the scalp into four segments. Up to the present time I have treated 40 cases by Sabouraud's method, giving in all 100 exposures with the pastilles. In every instance ${ }^{6}$ the hair has fallen regularly and completely during the third week, leaving the surface quite bald and free from both diseased and healthy hairs. Many of these scalps have not yet had time to recover their growth of hair but in those in which the defluvium took place more than six weeks ago the hair has begun to grow again and in all the earlier cases (both with and without the pastille) the hair-growth has attained its normal condition. In fact, my results are in accord with Sabouraud's statements that the hair begins to grow again six weeks after the defluvium is complete and that it is fully grown at the end of three months.

Provided then that the proper precautions are taken(1) that the length of exposure is not allowed to exceed the limit set by the right use of the pastille; (2) that no area or part of any surface is exposed more than once ; and (3) that the part exposed is kept at the proper fixed distance from the anticathode of the tube-there is no danger of permanent baldness or injury to the tissues. At the same time care must be taken that the exposure is sufficiently long or the fall of hair will not be complete and many diseased stumps will be left behind, requiring needling or other treatment afterwards. When a part only of the scalp is being treated the remainder must be anointed frequently with a mild parasiticide or the falling hairs from the diseased patch will spread the disease elsewhere ; this is explained by the fact that cultures of the fungus can be obtained from the depilated hairs showing that it has not been killed by the action of the rays.

In conclusion, there can be little doubt but that the method of treatment by the $x$ rays is about to supersede all other methods now that, with proper care, the risks of burning or of permanent baldness are no longer to be feared. The period of infectivity from the time that the patient comes under treatment-i.e., from the time of exposure to the completion of the defluvium-is reduced to three or four weeks. Even if the cure be considered to be effected only when the normal growth of hair has taken place the length of time under treatment is not more than three or four months. In the words of Sabouraud, "La teigne se guérissait en deux ans, elle se guérit en trois mois."

Weymouth-street, $\mathrm{w}$.

\section{A CASE OF POLYARTICULAR "QUIET EFFUSION."}

BY THOMAS BATTERSBY JOBSON, M.D.DUB., D.P.H. R.C.P.S. LOND.

THE subject of these notes, for which I cannot think of a better heading than the above, was a female, aged 24 years. For over a year she had been under my care for symmetrical effusions of the knee, the wrist, and the first phalangeal joints of the hand, and, as this subject has lately been brought into prominence by Sir William Bennett a short account of the case may be of some interest. With regard to the family history, although there was no history of swellings similar to those from which the patient suffered, there was a well-marked history of rheumatism. Her mother died from rheumatic fever and heart disease and both grandparents suffered from rheumatism. An aunt died from "dropsy." As to the previous history of the patient, as a child she suffered from severe headaches and from epistaxis. The first joint swelling she remembered was when she was nine years old. Her

6 The only exceptions were three cases in which, owing to a breakdown in the installation, the exposure had to cease before the pastille had reached the standard tint. wrists became greatly swollen, so much so that her friends thought she had put them out of joint. The medical attendant ordered them to be wrapped in flannel and called her disease "rheumatism." The joints remained big for a long time and to the best of her recollection this attack occurred during the winter. At the age of 11 years her knees became affected in the same way; they swelled but she suffered no pain and but little inconvenience. Soon after this the first inter-phalangeal joints of the hands became enlarged-all five joints of each hand just as they were last year when the photograph here reproduced was taken. All these swellings occurred in the winter time,

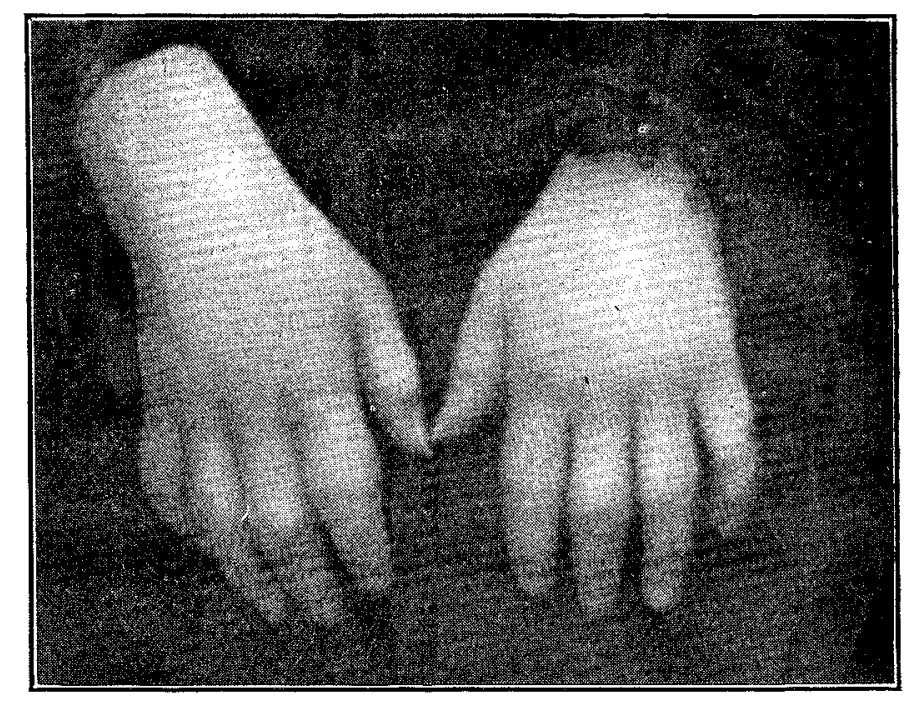

sometimes not coming on till as late as Christmas, but regularly subsiding with the onset of summer, when practically no trace of any enlargement remained. Regularly winter after winter these joint effusions recurred with more or less severity till she became quite accustomed to their yearly appearance and did not consult a medical man. Occasionally joints other than those mentioned above were affected. The elbows were a little swollen on one or two occasions. Once she suffered from pains in the back and her mother told her that she had swellings down the spine. The ankles were never enlarged, even to a slight degree. Until she was 20 years of age the patient felt but little inconvenience from these annual attacks but for the last four years she had been troubled with a considerable amount of stiffness and it was this that, by incapacitating her from work, caused her to seek medical advice. Also for a few years a considerable amount of dyspncea on exertion had accompanied the joint swellings. During the summer she could walk and run up stairs without getting out of breath. The patient had suffered on and off for years from amenorrhcea, but though she had been treated with benefit for this the joint effusions were not correspondingly improved. Also her menstrual troubles came on independently of the season of the year, whereas the joint affection occurred in the winter only. On the first occasion on which I saw the patient she was hysterical but this was the only time that any tendency to hysteria was noticed by me.

I first saw the patient in the winter of 1900. Her condition at that time was as follows. Both kneejoints were distended with fluid which readily yielded fluctuation. There was no redness, local heat, or tenderness on pressure. Great stiffness, both in the knees and in the back, was complained of. There was no cedema of the legs and the ankle-joints were quite normal. The wrist-joints were enlarged but not nearly so much as the knees. The most striking feature was the symmetrical enlargement of all the first inter-phalangeal joints of both hands. These looked like a row of "white swellings" across the fingers and kept the latter in a state of permanent abduction. The swellings presented the same features as the knee-joints and some idea of their appearance can be obtained from the illustration. The metacarpo-phalangeal joints were perhaps a little enlarged but very slightly. All the other joints in the body were normal. The patient suffered from constipation occasionally and also from indigestion. The urinary system was healthy, the urine containing no albumin or sugar. There was nothing abnormal in the lymphatic system. Except the tendency to hysteria the B B 3 
nervous system appeared healthy. The heart was sound and there was no obvious abnormality in the circulatory system, except a slight tendency to anæmia. This, however, was slight, her conjunctivæ were by no means pale, and the general colour of the face was good. The dyspnoea could not be entirely accounted for by anæmia. The specific gravity of the blood as determined by the chloroform-benzol method was from 1050 to 1055 and this, according to the table of Hammerschlag, gives a hæmoglobin percentage of 70-a figure very little below the average for women, the blood of the female being slightly more hydræmic than that of the male.

Treatment was as follows. The swellings could be reduced by pressure but they returned as soon as the pressure was removed. Rest in bed had no effect, so after a week's trial $I$ got the patient up, ordered moderate exercise, massage of the joints, and a mixture of iron and arsenic. In spite of treatment no real improvement in the condition of the joints took place till the spring of 1901.

Whether the swellings are due to a neurosis or whether they are caused by some form of arthritis is an interesting point and, personally, I incline to the former view. The present condition of the patient is similar to that described above. During the last winter, 1904-05, she had no swellings till March when her knees were again attacked.

The interesting points in the case may be recapitulated: the multiplicity of joints affected and their peculiar selection; the annual recurrence of the affection during the winter; the early age at which it commenced before menstruation; and the persistence of the effusions in spite of the menstrual functions being successfully treated.

Ilford.

\section{Climital antetes:}

\section{MEDICAL, SURGICAL, OBSTETRICAL, AND THERAPEUTICAL}

\section{NOTE ON A CASE OF ANEURYSM SIMULATING DYSPEPSIA.}

BY R. H. CORDYER, M.R.C.S. ENG., L.R.C.P. LOND.

THE patient, a man, aged 35 years, was admitted to the hospital complaining of "indigestion." He stated that for two years he had suffered from pain, usually coming on five or ten minutes after food and lasting for an hour or more. The discomfort was lessened by care in the selection of his diet but pain never quite left him and for some time previously to his admission he had restricted his diet almost entirely to fluids. The patient was a thin, worn man with a drawn, anxious face. The odour of his breath was heavy and his tongue was coated. His teeth were few and bad and he wore a plate of false teeth which he stated were not comfortable. His skin was inelastic and his bowels were constipated. His heart and lungs were sound and there was no history of syphilis.

On examination some pulsation was visible in the epigastric notch and extending over to the left of the middle line. On deep pressure over this area a sense of resistance was made out but no definite tumour. On auscultation over this region a faint blowing murmur was heard, localised to a space of about the size of a five-shilling piece. It was not heard in the iliac arteries and there was no diminution of the pulse wave. An $\mathrm{x}$ ray photograph gave no shadow.

Under treatment, for some time the patient seemed to improve but latterly he complained of the increasing pain both in the epigastrium and in the back. These pains rapidly became worse and often took place at times quite unconnected with food, occurring often at night and disturbing his sleep and necessitating the use of morphine. One night mearly three weeks after admission the patient suddenly died.

Necropsy.-A post-mortem examination showed an aneurysm of about the size of a small pear involving the whole of the coliac axis artery and the anterior wall of the aorta. It lay on the spine between the two crura, close up to the aortic opening in the diaphragm and partly covered by the posterior wall of the stomach. The splenic artery came right out of the wall of the sac, the cavity of which was nearly filled with ante-mortem clot. The wall of the aneurysm had ruptured and the peritoneal cavity was full of blood. The stomach seemed quite healthy.

The curious point about this case was that almost all the symptoms were referred to the digestive organs, which, I think, were little if at all affected. The bad teeth, coated tongue, and constipation all seemed to point in the same direction. The probable explanation seemed to be in the close relation of the sac to the stomach wall. It is conceivable that food by setting up peristaltic contractions would cause pain and irritation in the sac. Bland and unirritating, easily digested foods, such as peptonised milk, would by causing less peristalsis cause less pain. This latter fact would account for the apparent improvement under careful dieting.

Aldershot.

\section{NOTE ON A CASE OF EMPYEMA TREATED BY PNEUMOCOCCUS TACCINE.}

By Thomas Glover Lyon, M.A., M.D. Cantab., PHYSICLAN TO THE CITY OF LONDON HOSPITAL FOR DISEASES OF THE CHEST, VICTORIA PARK.

THE patient was a man, aged 23 years, of temperate habits. On Feb. 22nd, 1905, Mr. J. L. Lawry (then house physician to the case) resected a rib, letting out two and a half pints of blood-stained inodorous pus. The acute symptoms were at once relieved but the subsequent progress of the case proved unsatisfactory. The patient remained of a bad colour and did not gain strength. The discharge became offensive and constant in quantity, about half an ounce daily. A probe could be inserted four inches into the sinus and provoked coughing. Cultures of the discharge showed a pure growth of diplococcus pneumonix and it was determined to try the effect of the inoculation treat ment after Dr. A. E. Wright's method. ${ }^{1}$ This was com. menced on April 26th-i.e., nine weeks after the resection of rib. A record of the details of the injections and their effect upon the opsonic index of the patient's blood will be seen recorded upon the accompanying chart.

Chart of Variations in Opsonic Tndex.

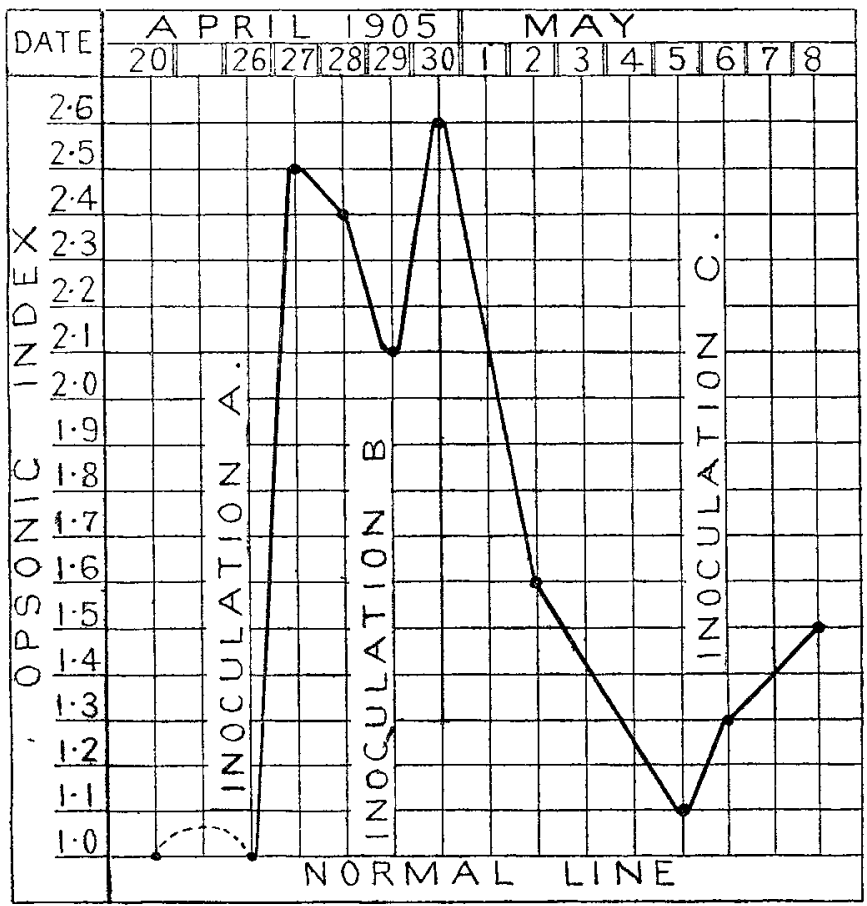

A, Inoculation 100 millions pneumococci. B, Inoculation 200 million pneumococci. c, Inoculation 100 millions pneumococci.

Immediately after the first injection a remarkable change occurred in the condition of the patient. He rapidly gained strength and weight and the discharge ceased to be offencive. At the end of a fortnight after the first inoculation the wound had healed and the patient left the hospital on May 10th to resume his ten hours' daily work. It may be added that there was no constitutional or local disturbance attending the inoculations. The temperature, respiration,

1 The Lancer, August 6th (p. 411) and Oct. 22nd (p. 1138), 1904. 